\title{
Built-In Reliability Design of a High-Frequency SiC MOSFET Power Module
}

\author{
J. Li, E. Gurpinar, S. Lopez-Arevalo, A. Castellazzi \\ Power Electronics, Machines and Control Group \\ University of Nottingham \\ Nottingham, UK \\ alberto.castellazzi@nottingham.ac.uk
}

\begin{abstract}
A high frequency SiC MOSFET-based threephase, 2-level power module has been designed, simulated, assembled and tested. The design followed a built-in reliability approach, involving extensive finite-element simulation based analysis of the electro-thermo-mechanical strain and stress affecting the switch during both manufacturing and operation: structural simulations were carried out to identify the materials, geometry and sizes of constituent parts which would maximize reliability. Following hardware development, functional tests were carried out, showing that the module is suitable for high switching frequency operation without impairing efficiency, thus enabling a considerable reduction of system-level size and weight.
\end{abstract}

Keywords - SiC MOSFET, multi-chip power modules, reliability.

\section{POWER Module DESIGN}

A $1.2 \mathrm{kV} \mathrm{SiC-MOSFET} \mathrm{based} \mathrm{three-phase} \mathrm{half-}$ bridge power module was designed, specifically for avionic applications, where improved gravimetric and volumetric power density and efficiency are highly appreciated.

The structure of one phase switch is shown in Fig. 1 , with indication of assembly layers and location of interconnection pins. Each switch allocates two SiC MOSFETs, which are soldered on the substrate top metallization (Sub_Metal_Top in Fig. 1 b)) together with the power and drive terminals (S-Pins); the substrate bottom metallization is soldered onto the module baseplate. All the solder joints are made of eutectic tin-silver (Sn-3.5Ag) solder of constant $100 \mu \mathrm{m}$ thickness. Because this module does not target specifically high-temperature applications, aluminum ( $\mathrm{Al})$ bond-wire were used for interconnections to the device top-side, with diameter of $125 \mu \mathrm{m}$.

Two types of substrates commonly used in the construction of power modules have been considered, namely Aluminum-Nitride (AlN) and Silicon-Nitride $\left(\mathrm{Si}_{3} \mathrm{~N}_{4}\right)$. Table I summarizes the main characteristics of interest for the two materials: $\mathrm{Si}_{3} \mathrm{~N}_{4}$ has higher flexural strength than AlN and is thus typically processed in thinner layers than AlN for use in building power modules; this also implies that, although $\mathrm{Si}_{3} \mathrm{~N}_{4}$ has a lower thermal conductivity than $\mathrm{AlN}$, the equivalent

\author{
L. Mills \\ Semelab \\ TT-Electronics \\ Lutterworth, UK \\ liam.mills@semelab-tt.com
}

thermal resistance of the substrates is comparable if the difference in thickness is taken into account. Here, both experiment and simulations are used to inform the choice on most reliable solution.

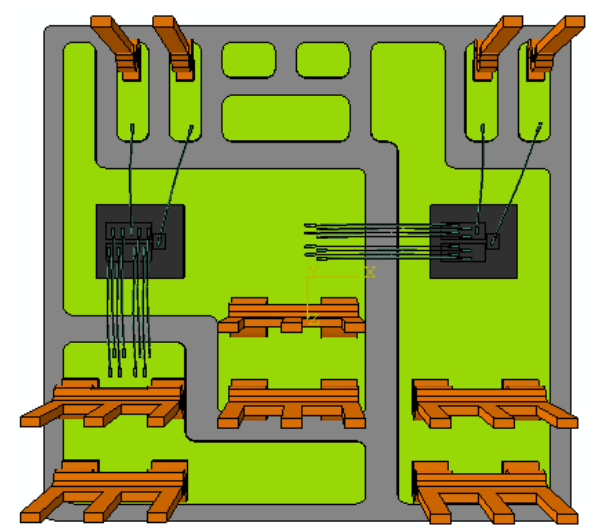

a)

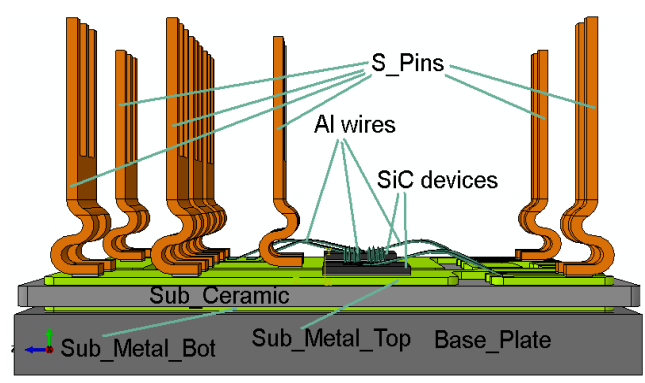

b)

Fig. 1. One-phase SiC switch: a) top view, b) side view.

TABLE I

THERmo-Mechanical CHARACTERISTICS OF SubstRate CERAMICS

\begin{tabular}{|c|c|c|c|c|}
\hline & $\begin{array}{c}\text { Thermal } \\
\text { Conductivity } \\
(\mathrm{W} / \mathrm{m} \cdot \mathbf{k})\end{array}$ & $\begin{array}{c}\text { Flexural } \\
\text { Strungth } \\
(\mathrm{MPa})\end{array}$ & $\begin{array}{c}\text { Fracture } \\
\text { Toughness } \\
\text { (MPam1/2) }\end{array}$ & $\begin{array}{c}\text { CTE } \\
(\mathrm{ppm} / \text { degree-C) }\end{array}$ \\
\hline AIN & 170 & 400 & 2.7 & 4.5 \\
\hline $\mathrm{Si}_{3} \mathrm{~N}_{4}$ & 60 & 850 & 5.0 & 2.7 \\
\hline
\end{tabular}


Preliminary experimental testing was carried out on batches of the two types of assemblies, with different thicknesses of copper tracks deposited onto them. The tiles were subjected to passive thermal cycling and $\mathrm{Cu}$ tracks detachment/peel-off was used as an indication of failure. The results are summarized in Table II and give a clear indication that $\mathrm{Si}_{3} \mathrm{~N}_{4}$ tiles can withstand a much higher number of cycles before degradation and failure intervenes. Also, it is interesting to note that the thicker the $\mathrm{Cu}$ tracks, the shorter the number of cycles to failure.

TABLE II

Simulation CASES With CONSIDERATION OF SUBSTRATES AND BUMP SHAPES

\begin{tabular}{|c|c|c|c|c|c|}
\hline \multicolumn{2}{|c|}{} & \multicolumn{4}{|c|}{ Cu Plate Thickness } \\
\cline { 2 - 6 } \multicolumn{2}{|c|}{} & $0.2 \mathrm{t}$ & $0.3 \mathrm{t}$ & $0.4 \mathrm{t}$ & $0.5 \mathrm{t}$ \\
\hline \multirow{4}{*}{$\begin{array}{c}\text { Ceramic } \\
\text { Substrate } \\
\text { Material }\end{array}$} & $\begin{array}{c}\text { AIN } \\
0.635 \mathrm{t}\end{array}$ & 300 & 200 & Failure & Failure \\
\cline { 2 - 6 } & $\begin{array}{c}\text { Si3N4 } \\
0.32 \mathrm{t}\end{array}$ & $>3000$ & $>3000$ & $>3000$ & $>3000$ \\
\hline
\end{tabular}

Condition: -40 deg.C (30 min.) to $125 \mathrm{deg} . \mathrm{C}$ (30 min.)

Failure: Cu plate detached after brazing

Finite element (FE) modeling and simulation are employed to investigate the effects of the type and the thickness of substrate and base plate used on the entity of the maximum thermo-mechanical stress and its distribution. Simulations target the analysis of the thermal and thermo-mechanical performance of the assembled power module. The considered simulation cases are listed in Table III.

TABLE III

Simulation CASES With CONSIDERATION OF SUBSTRATES AND BUMP SHAPES

\begin{tabular}{|c|c|c|c|c|}
\hline No & $\begin{array}{l}\text { Sub Ceramic } \\
\text { Thickness }\end{array}$ & $\begin{array}{l}\text { Sub Metal } \\
\text { Bot } \\
\text { Thickness }\end{array}$ & $\begin{array}{l}\text { Sub Metal } \\
\text { Top } \\
\text { Thickness }\end{array}$ & $\begin{array}{l}\text { Base Plate } \\
\text { Thickness }\end{array}$ \\
\hline A1 & & $0.3 \mathrm{~mm} \mathrm{Cu}$ & $0.4 \mathrm{~mm} \mathrm{Cu}$ & \\
\hline & & & & \\
\hline A3 & & & & $2 \mathrm{~m}$ \\
\hline A4 & 0.635 & & $\mathrm{Cu}$ & $2 \mathrm{~m}$ \\
\hline A5 & & $.2 \mathrm{~mm} \mathrm{Cu}$ & $0.3 \mathrm{~mm} \mathrm{Cu}$ & $2 \mathrm{mr}$ \\
\hline A6 & & & $\mathrm{m} \mathrm{Cu}$ & $1 \mathrm{SiC}-9$ \\
\hline B1 & & & $0.4 \mathrm{~m}$ & iC-9 \\
\hline B2 & & & $0.4 \mathrm{~ms}$ & $\mathrm{SiC}-1$ \\
\hline B3 & & $.3 \mathrm{~mm} \mathrm{Cu}$ & $0.4 \mathrm{~mm} \mathrm{Cu}$ & $2 \mathrm{~mm}$ AlSiC-9 \\
\hline B4 & & $.2 \mathrm{~mm} \mathrm{Cu}$ & $0.3 \mathrm{~mm} \mathrm{Cu}$ & $3 \mathrm{~mm}$ AlSiC-9 \\
\hline B5 & & $\mathrm{n} \mathrm{Cu}$ & $0.4 \mathrm{~m}$ & AlSiC-9 \\
\hline B & & $\mathrm{Cu}$ & $0.3 \mathrm{n}$ & $\mathrm{SiC}-9$ \\
\hline B7 & & $0.3 \mathrm{~mm} \mathrm{Cu}$ & $0.3 \mathrm{~mm} \mathrm{Cu}$ & $2 \mathrm{~mm} \mathrm{AlSiC}-\mathrm{C}$ \\
\hline
\end{tabular}

The first one is $0.4 \mathrm{~mm}$ and $0.3 \mathrm{~mm}$ thick active brazed $\mathrm{Cu}$ on both sides of $1 \mathrm{~mm}$ or $0.635 \mathrm{~mm}$ thick AlN tile. The second one is $0.4 \mathrm{~mm}$ and $0.3 \mathrm{~mm}$ thick or $0.3 \mathrm{~mm}$ and $0.2 \mathrm{~mm}$ active brazed $\mathrm{Cu}$ on both sides of $0.3 \mathrm{~mm}$ or $0.635 \mathrm{~mm}$ thick $\mathrm{Si}_{3} \mathrm{~N}_{4}$ tile, respectively. Also, two types of base plate materials have been considered: AlSiC-9 and AlSiC-12 composites. For each of the two composites, two thicknesses of $3 \mathrm{~mm}$ and $2 \mathrm{~mm}$ for the Base_Plate were selected and compared in order to reduce the stress/strain accumulation within the solder joints.

The characteristics of the material used for the solder layer, Lead $(\mathrm{Pb})$-Tin $(\mathrm{Sn})$-Silver $(\mathrm{Ag})$ solder of the composition $62 \mathrm{~Pb} 36 \mathrm{Sn} 2 \mathrm{Ag}$, are summarized in Table IV.

TABLE IV

SOLDER PROPERTIES

\begin{tabular}{|l|c|}
\hline Liquidus Temperature $\left({ }^{\circ} \mathrm{C}\right)$ & 179 \\
\hline Density $(\mathrm{gm} / \mathrm{cm} 3)$ & 8.41 \\
\hline Electrical Conductivity $(1.72 \mu \Omega-\mathrm{cm}(\%$ of IACS) & 11.9 \\
\hline Thermal Conductivity @ $85^{\circ} \mathrm{C}\left(\mathrm{W} / \mathrm{cm}-{ }^{\circ} \mathrm{C}\right)$ & 0.5 \\
\hline $\begin{array}{l}\text { Thermal Coefficient of Expansion @ } 20^{\circ} \mathrm{C} \\
\left(\mathrm{PPM} /{ }^{\circ} \mathrm{C}\right)\end{array}$ & 27 \\
\hline Tensile Strength (PSI) & 7000 \\
\hline Shear Strength (PSI) & 7540 \\
\hline Specific Heat Capacity $\left(\mathrm{J} / \mathrm{g}-{ }^{\circ} \mathrm{C}\right)$ & 0.167 \\
\hline
\end{tabular}

Modeling and simulation were carried out using well-established commercially available tools (e.g., Abaqus, Ansys). Fig. 2 a) shows the numerical structural model (meshed) of the switch: the largest brick element is $0.5 \times 0.5 \times 1.5 \mathrm{~mm}$, and the smallest is $0.5 \times 0.25 \times 0.025 \mathrm{~mm}$. Here, the largest brick element is $0.5 \times 0.5 \times 1.5 \mathrm{~mm}$, and the smallest is $0.5 \times 0.25 \times 0.025 \mathrm{~mm}$. S4R shell elements of $0.5 \times 0.5 \mathrm{~mm}$ or $0.5 \times 0.25 \mathrm{~mm}$ in size were also used to discretize the nickel-phosphorous (NiP) finishing on the surfaces of the substrates, and in both the $\mathrm{Al}$ and $\mathrm{Ni}$ metallization on two sides of the MOSFETs respectively.

The assembly was first subjected to a predefined temperature profile of $221^{\circ} \mathrm{C}$ down to $25^{\circ} \mathrm{C}$ for $3 \mathrm{~min}$ to simulate the stress and strain developed during the reflow process. In this stage, all the $\mathrm{Al}$ wire bonds were deactivated and therefore no strain/stress was developed on them. Power losses of one MOSFET are shown in Fig. $2 \mathrm{~b})$. These losses were considered as heating sources to simulate the thermal performance of the assembly during a realistic mission profile. They were also taken in account in the heat exchange boundary condition. For this boundary condition, a heat exchange coefficient of $5000 \mathrm{~W} \mathrm{~m} \mathrm{~m}^{-2} \mathrm{~K}^{-1}$ was applied to the bottom surface of the base plate, corresponding to typical heat-sink cooling conditions in our lab experiments. The temperature field obtained from the thermal simulation was used as input to simulate the development of stress/strain in the assembly during two cycles of the mission profile. Thermal and mechanical properties of all the materials used in the thermo-mechanical simulation were taken from either references [1-3] or the datasheets of the materials commercially available. Chaboche's plastic model was 
used to describe the mechanical properties of both the $\mathrm{Cu}$ and $\mathrm{Al}$. The properties of $\mathrm{Al}$ were applied to both the $\mathrm{Al}$ wire bonds and the Al metallization on the front side of the MOSFETs. Anand's creep model was used to describe the mechanical properties of the $\mathrm{Sn}-3.5 \mathrm{Ag}$ solder alloy.

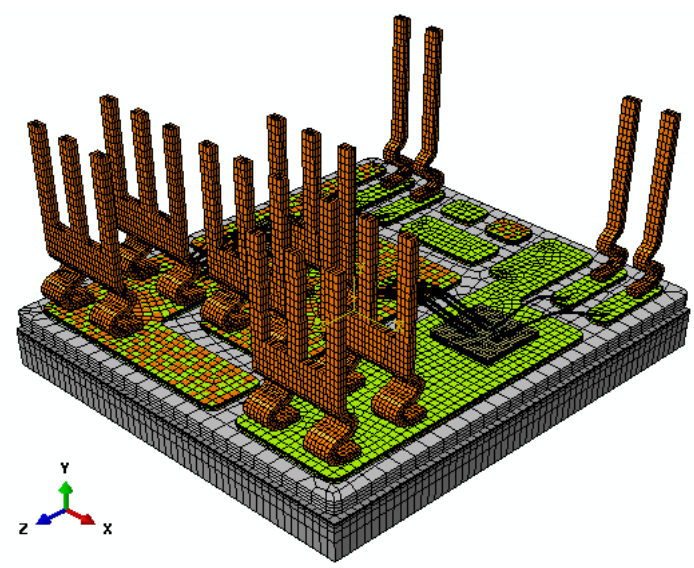

a)

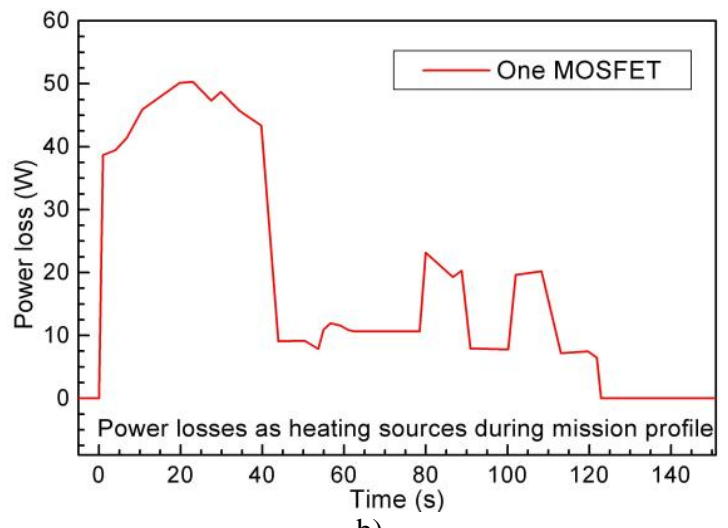

b)

Fig.2. a) Representative meshing system to discretize the designed switch module. b) Power loss of one MOSFET during a realistic mission profile.

\section{THERMO-MECHANICAL SIMULATION}

For all simulation cases during the mission profile, the highest junction temperature was observed on one MOSFET at 23.01s. The simulation shown is mainly concerned with the stress and strain developed in all solder joints. Simulation results reveal that the maximum von Mises stress in the solder joint between the substrate and the base plate are larger than those in the two solder joints used for attaching the two SiC MOSFETs on the substrate. The maximum creep strain accumulation in the former solder joint is significantly larger than that in the latter two solder joints after the first cycle of the mission profile. However, and depending on the simulation cases, the maximum creep strain accumulation in the former solder joint may be higher or lower than that in the latter two solder joints after the second cycle of the mission profile.

Fig. 3 shows the von Mises stresses and creep strains obtained from simulations in all the solder joints for case A1 after two cycles of the mission profiles. Table $\mathrm{V}$ compares the simulation cases for the highest junction temperatures of the MOSFETs and the maximum von Mises stress and creep strain developed in the solder joint between the substrate and the base plate. In Table V, $\mathrm{T}_{\mathrm{J}, \max }$ is for the highest junction temperature of the MOSFETs during the mission profile; $\mathrm{S}_{\max 0}, \mathrm{~S}_{\max 1}$ and $S_{\max 2}$ represent the maximum von Mises stress and $\varepsilon_{\max 0}$, $\varepsilon_{\max 1}$ and $\varepsilon_{\max 2}$ represent the maximum creep strain in the solder joint of the as-reflowed assembly and the same one after one and two cycles of the mission profile; and $\Delta \varepsilon_{\max 1}=\varepsilon_{\max 1}-\varepsilon_{\max 0}, \Delta \varepsilon_{\max 2}=\varepsilon_{\max 2}-\varepsilon_{\max 1}$.

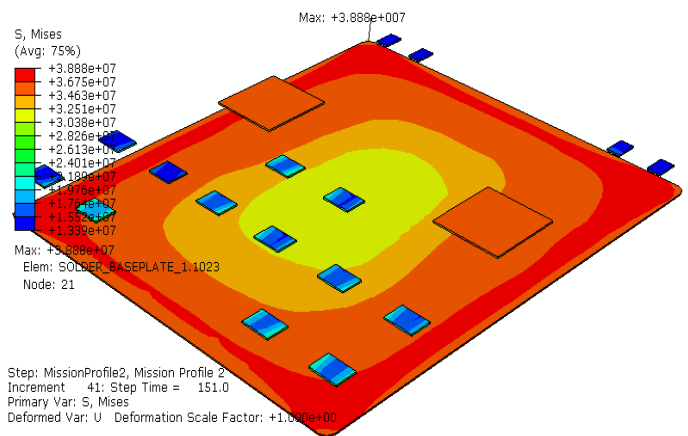

a)

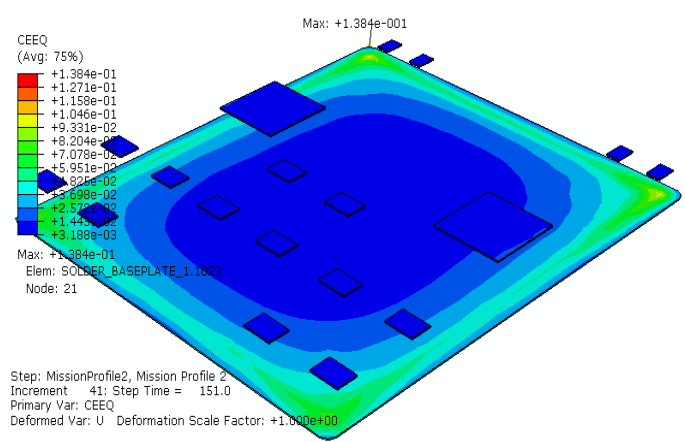

b)

Fig. 3. Simulation results of (a) von Mises stresses and (b) creep strains within all solder joints for simulation case A1 after two cycles of the mission profile.

According to these results, the best design is achieved when the base-plate is $2 \mathrm{~mm}$ thick AlSiC-9 and the substrate is AlN-based with $0.635 \mathrm{~mm}$ thick AlN tile (case A4). In this case, the highest junction temperature of the MOSFET is only $0.6^{\circ} \mathrm{C}$ higher than that in simulation case A1; however, the maximum creep strains and creep strain accumulations dominating the reliability of the critical solder joint in the module would be significantly lower than those in the other simulation cases.

In view of both experimental and simulation results, however, and more particularly due to the relatively small difference in the stress and strain values for the 
TABLE V

Comparison of The Highest Junction Temperatures of The MOSFETs and The MaXimum von Mises Stress, Creep Strain and Creep Strain Accumulation In The Solder Joint Between The Substrate and Base Plate For The 13 Simulation Cases

\begin{tabular}{|c|c|c|c|c|c|c|c|c|c|}
\hline Case & $\begin{array}{c}\text { TJ,MAX }_{\text {J }} \\
(\mathrm{K})\end{array}$ & $\begin{array}{c}\mathrm{S}_{\max 0} \\
(\mathrm{MPa}) \\
\end{array}$ & $\begin{array}{c}S_{\max 1} \\
(\mathrm{MPA})\end{array}$ & $\begin{array}{c}\mathrm{S}_{\mathrm{MAX} 2} \\
(\mathrm{MPa})\end{array}$ & $\begin{array}{c}\varepsilon_{\mathrm{MAX} 0} \\
(\%)\end{array}$ & $\begin{array}{c}\varepsilon_{\mathrm{MAX} 1} \\
(\%)\end{array}$ & $\begin{array}{c}\varepsilon_{\text {MAX2 } 2} \\
(\%)\end{array}$ & $\begin{array}{c}\Delta \varepsilon_{\operatorname{MAX} 1} \\
(\%)\end{array}$ & $\begin{array}{c}\Delta \varepsilon_{\operatorname{MAX} 2} \\
(\%)\end{array}$ \\
\hline A1 & 363.2 & 42.6 & 39.5 & 38.9 & 12.65 & 13.40 & 13.84 & 0.75 & 0.44 \\
\hline $\mathrm{A} 2$ & 363.9 & 44.2 & 41.6 & 40.7 & 18.84 & 19.67 & 20.17 & 0.83 & 0.50 \\
\hline A3 & 363.8 & 41.0 & 38.2 & 37.6 & 6.87 & 7.25 & 7.52 & 0.37 & 0.27 \\
\hline A4 & 363.8 & 41.3 & 37.9 & 37.4 & 6.83 & 7.10 & 7.23 & 0.27 & 0.13 \\
\hline A5 & 365.6 & 41.3 & 38.6 & 38.1 & 7.65 & 8.13 & 8.41 & 0.48 & 0.28 \\
\hline A6 & 364.8 & 40.8 & 37.9 & 37.4 & 7.07 & 7.35 & 7.49 & 0.28 & 0.14 \\
\hline B1 & 366.4 & 42.6 & 39.1 & 38.4 & 10.96 & 11.80 & 12.26 & 0.84 & 0.46 \\
\hline B2 & 367.4 & 44.2 & 40.5 & 39.9 & 16.79 & 17.66 & 18.12 & 0.87 & 0.46 \\
\hline B3 & 367.6 & 41.3 & 38.1 & 37.6 & 7.32 & 7.70 & 8.01 & 0.38 & 0.31 \\
\hline B4 & 368.7 & 43.0 & 39.6 & 41.2 & 12.10 & 12.88 & 13.32 & 0.78 & 0.44 \\
\hline B5 & 370.6 & 42.5 & 39.0 & 38.4 & 8.98 & 9.61 & 9.98 & 0.63 & 0.37 \\
\hline B6 & 373.4 & 42.4 & 39.5 & 39.0 & 10.25 & 10.88 & 11.27 & 0.63 & 0.39 \\
\hline B7 & 372.6 & 42.5 & 39.0 & 38.4 & 9.17 & 9.81 & 10.19 & 0.64 & 0.38 \\
\hline
\end{tabular}

simulation results using $\mathrm{AlN}$ and $\mathrm{Si}_{3} \mathrm{~N}_{4}$ (e.g., case $\mathrm{A} 1$ in comparison with case B3), Si3N4 substrates were retained as the best solution for built-in reliability module development.

\section{HARDWARE DEVELOPMENT AND TEST}

\section{A. Development}

Fig. 4 a) shows details of the assembled switches and module. The module of Fig. 4 b) was later filled with a silicone-based dielectric material to provide the required isolation and insulation. Finally it was fully encapsulated by using a plastic lid leading to the final product of Fig. $4 \mathrm{c}$ ). The final module as assembled for both functional and reliability testing weighs $126.5 \mathrm{~g}$ $\pm 0.5 \mathrm{~g}$. In view of the specified goal of lightweight development, this is a very satisfactory results, competitive with presently upcoming commercial solutions. A noteworthy feature of the module is the complete separation of the power and driving terminals and current loops. All power terminals were finally implemented with single connectors, doubled to reduce parasitic inductance and enable high switching frequency.

The module has been subjected to both functional testing in inverter operation and to temperature cycles for technology validation. Here, the results of functional testing are reported to demonstrate the high frequency capability and good thermal performance. Reliability tests are still ongoing at the time of submission.

\section{B. Test}

A flexible test setup was designed to test a number of modules that have been manufactured. The setup comprises of four electrolytic capacitors $(350 \mathrm{~V}, 3.3 \mathrm{mF}$ each) with discharge and balancing resistors ( $47 \mathrm{k} \Omega$ each), and the $\mathrm{SiC}$ module power pins are mounted directly onto the power plane. The schematic is shown in Fig. 5. Fig. 6 shows a picture of the test setup.

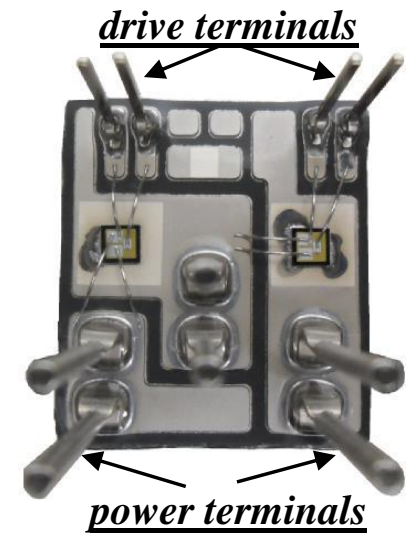

a)

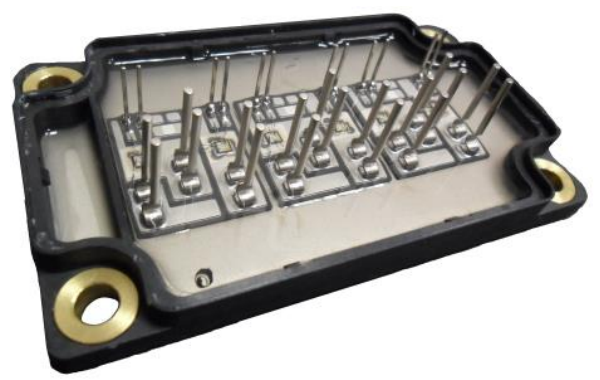

b)

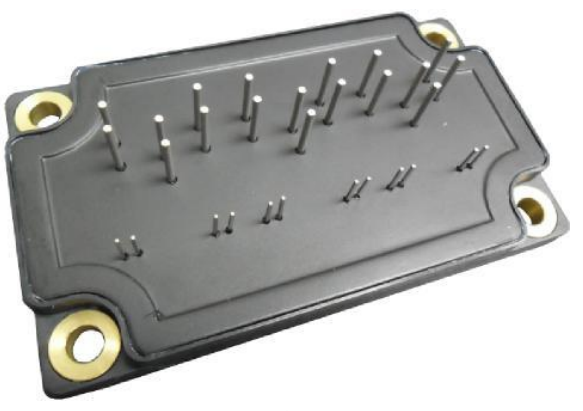

c)

Fig. 4. Assembled switches a), full power module b) and encapsulated device c). 


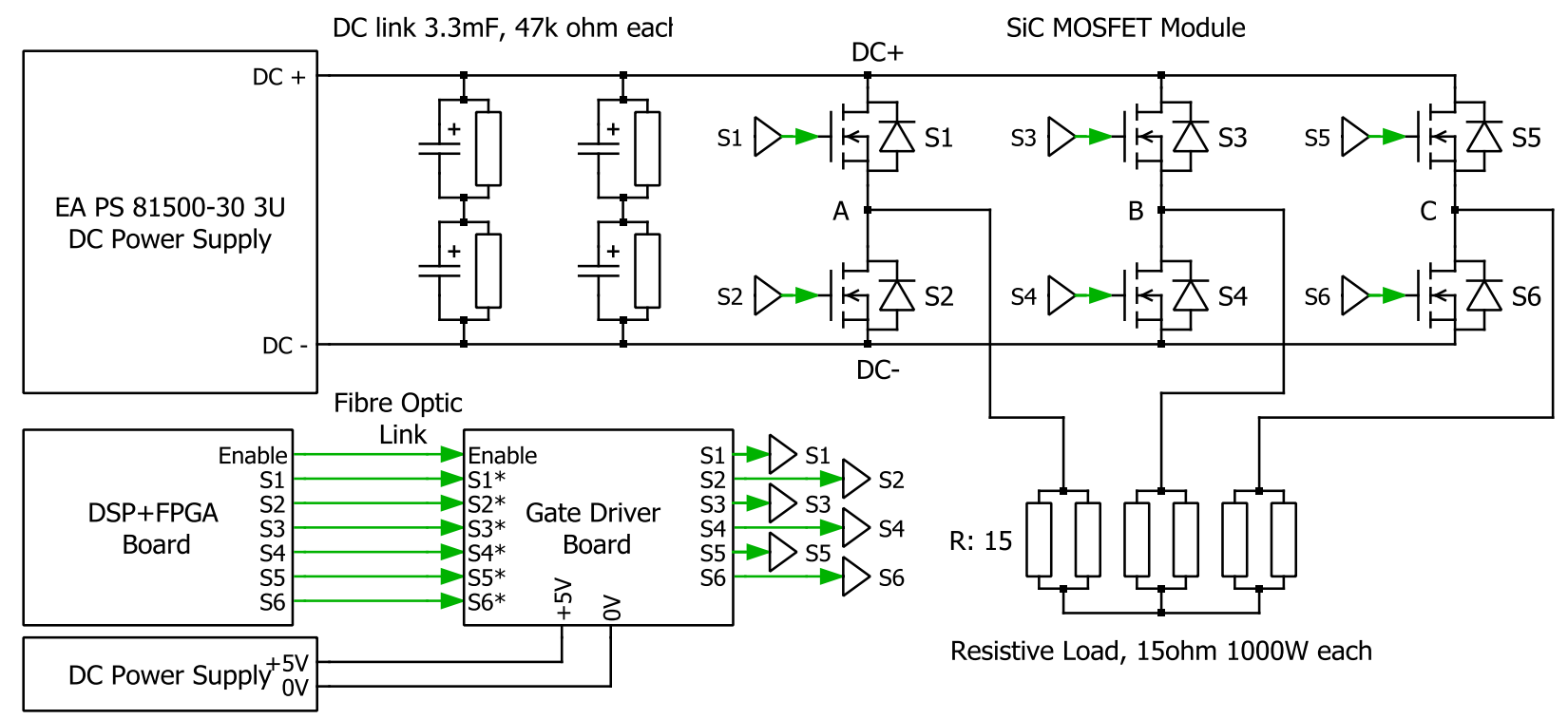

Fig. 5. Schematic of the test circuit.

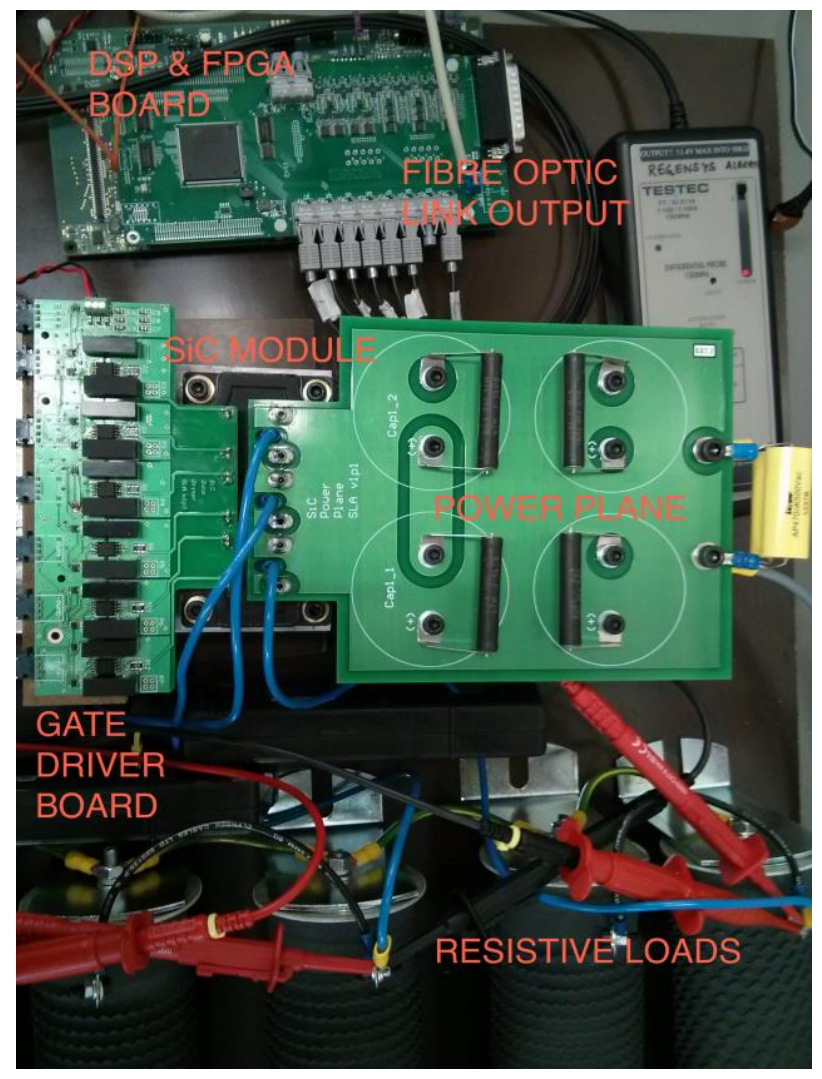

Fig. 6. Photograph of the test set-up.

The inverter was tested in open loop; the necessary PWM drive signals are generated by a DSP and FPGA control platform with programmable deadtime values. The PWM signals are transmitted to a gate driver board, which is mounted directly onto the $\mathrm{SiC}$ module gate pins, through fiber optic cables in order to minimize the noise interference at high switching frequencies. An isolated gate drive IC supplies $+22 \mathrm{~V}$ to turn-on and $-3.1 \mathrm{~V}$ to turn-off each individual $\mathrm{SiC}$ MOSFET. The input DC link voltage is $540 \mathrm{~V}$ to represent the DC bus in an avionic systems. The inverter was tested at full load $(6 \mathrm{~kW})$ and half load $(3 \mathrm{~kW})$ conditions. The output inductive filter was $3 \mathrm{mH}$. Output phase-to-neutral RMS voltage is set to $115 \mathrm{~V}$ with $50 \mathrm{~Hz}$ fundamental frequency. Tests were run at increasing switching frequencies: $5,10,20,40,60,80$ and $100 \mathrm{kHz}$. Fig. 7 shows the three phase current components for a switching frequency of $5 \mathrm{kHz}$.

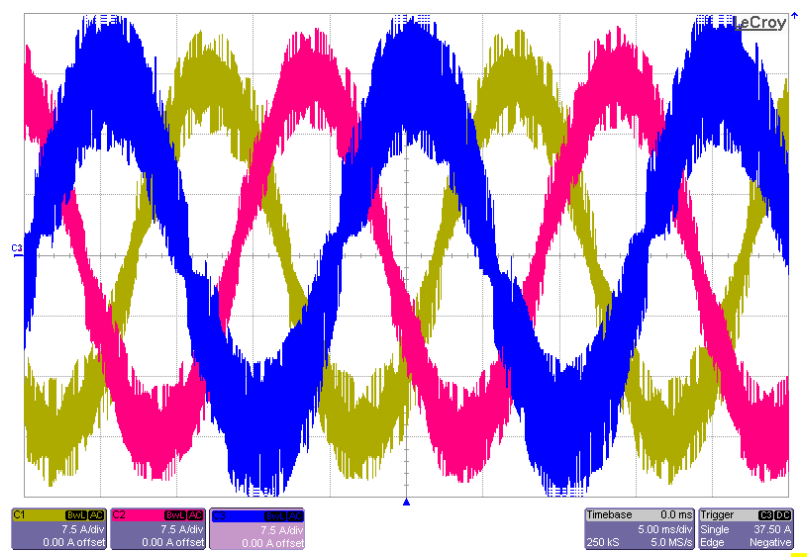

Fig. 7. Phase current waveforms at a switching frequency of 5 $\mathrm{kHz}$.

The output phase voltage and current, and the drainsource $\left(\mathrm{V}_{\mathrm{ds}}\right)$ and gate-source voltage $\left(\mathrm{V}_{\mathrm{gs}}\right)$ waveforms of each SiC MOSFET were also captured. The turn-on and turn-off waveforms of the SiC MOSFET at full load and $100 \mathrm{kHz}$ switching frequency are shown in Fig. 8 a) and b), respectively. These waveforms show that the turn-on and turn-off times of the power switches are less than $60 \mathrm{~ns}$ at full load. 


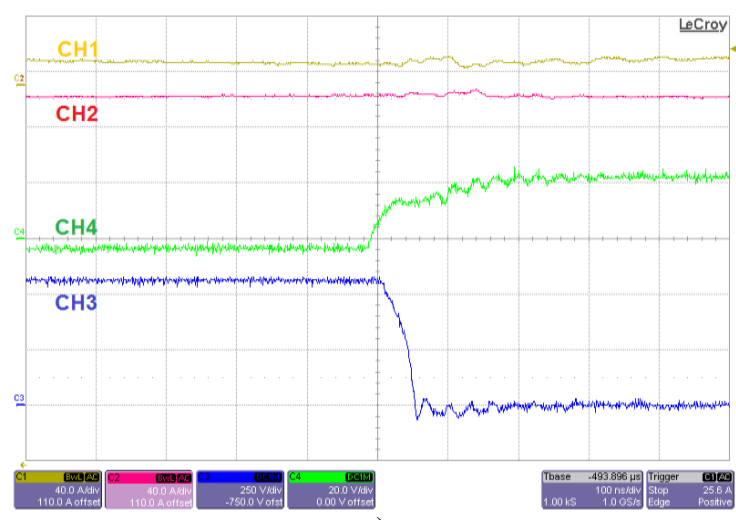

a)

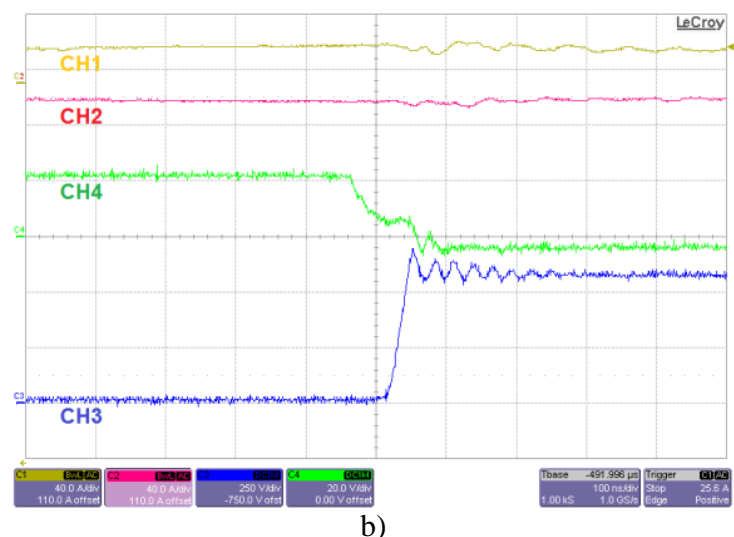

b)

Fig. 8. Turn-on, a), and turn-off waveforms, b), at $\mathrm{f}_{\mathrm{sw}}=100 \mathrm{kHz}$, full-load $(\mathrm{CH} 1$ and $\mathrm{CH} 2$ : Current in phase $\mathrm{A}$ and $\mathrm{B}, 40 \mathrm{~A} / \mathrm{div}$, $\mathrm{CH} 3: \mathrm{V}_{\mathrm{ds}}=250 \mathrm{~V} / \mathrm{div}, \mathrm{CH} 4: \mathrm{V}_{\mathrm{gs}}=20 \mathrm{~V} / \mathrm{div}$, timebase $\left.=100 \mathrm{~ns} / \mathrm{div}\right)$.

In a final test, we removed altogether the inductive filter from the load. Fig. 9 shows the output current waveforms of all three phases at full load and $100 \mathrm{kHz}$ switching frequency in this condition. Although the load at the output of the converter is purely resistive, due to leakage inductance at the output cables and resistors, and high switching frequency, the output phase currents become continuous. Clearly, the ripple is not contained, but these measurements give a very clear indication of the dramatic reduction in inverter volume and size which can be enabled by the high-frequency $\mathrm{SiC}$ power module.

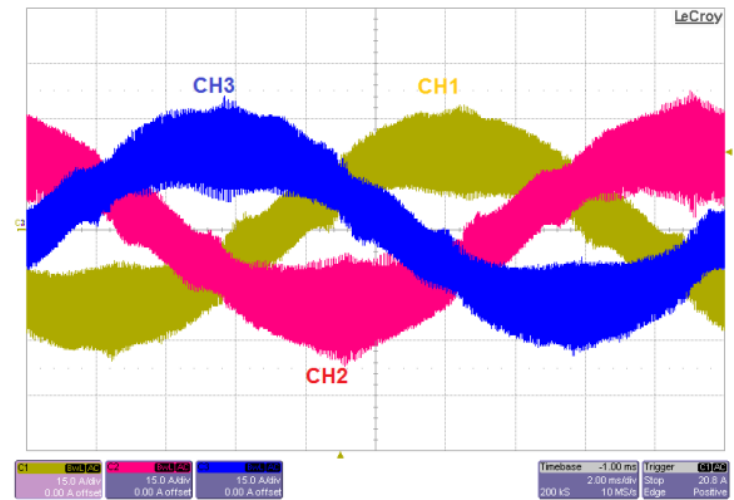

Fig. 9. Output current waveforms at $\mathrm{f}_{\mathrm{s}}=100 \mathrm{kHz}$, full-load $(\mathrm{CH} 1=$ Phase A current $15 \mathrm{~A} / \mathrm{div}, \mathrm{CH} 2=$ Phase $\mathrm{B}$ current 15 $\mathrm{A} / \mathrm{div}, \mathrm{CH} 3=$ Phase $\mathrm{C}$ current $15 \mathrm{~A} / \mathrm{div}$, timebase $=2 \mathrm{~ms} / \mathrm{div})$.
Finally, Fig. 10 reports the measured efficiency at full load as a function of the switching frequency. A decrease of only $2.5 \%$ (i.e., $15 \mathrm{~W}$ ) is measured for a twentyfold increase in the switching frequency (from 5 to $100 \mathrm{kHz}$ ), which is directly attributed to the $\mathrm{SiC}$ device characteristics [4].

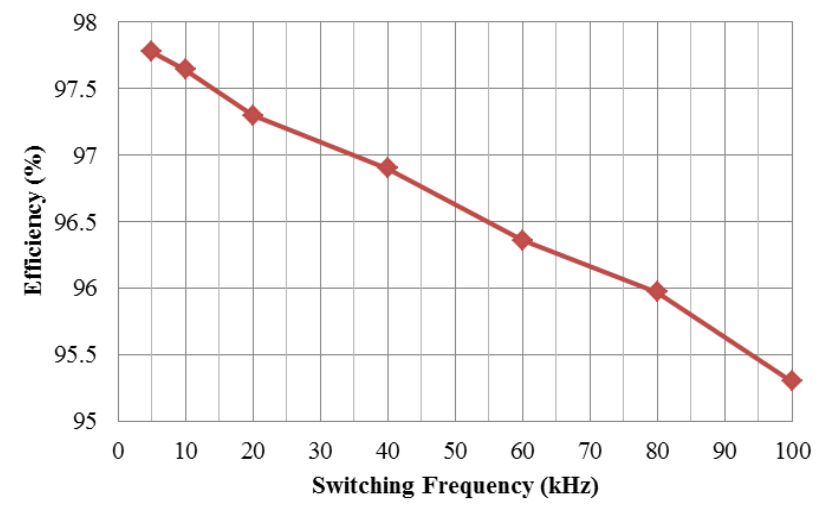

Fig. 10. Efficiency curve of power module at $6 \mathrm{~kW}$ output power.

To complete experimental characterization, the $\mathrm{SiC}$ power module was dismounted from the heatsink and the temperature at the baseplate was measured under different operational conditions. To avoid failure, the maximum allowed baseplate temperature was around $90{ }^{\circ} \mathrm{C}$. This corresponded to the following test conditions: $P_{\text {OUT }}=2.5 \mathrm{~kW}$ at $\mathrm{f}_{\mathrm{s}}=5 \mathrm{kHz}$ and $P_{\text {OUT }}=1.5 \mathrm{~kW}$ at $\mathrm{f}_{\mathrm{s}}=40$ and $80 \mathrm{kHz}$. The baseplate temperature distribution corresponding to these test conditions is given in Fig. 11 a), b) and c). All results highlight a very even temperature distribution, with maximum at the center in line with the expectations, and the capability of the module to work properly and efficiently with noticeable baseplate temperatures, that is, minimum cooling requirements, at high switching frequencies and power levels.

\section{CONCLUSION}

In this paper, the design, the thermo-mechanical modeling using finite element analysis and, simulation and experimental results of a lightweight SiC MOSFET module are presented. Simulation results using finite element suggests that the best design is obtained when the Base_Plate is based on AlSiC-9 with a thickness of $2 \mathrm{~mm}$ and the substrate is AlN-based with $0.635 \mathrm{~mm}$ thick AIN tile. The module has been tested successfully at full and half load operating conditions using a switching frequency of up to $100 \mathrm{kHz}$. Experimental results show that the designed power module successfully operates in a wide switching frequency range with high-efficiency at full-load and half-load operating conditions, making it ideal for all applications which prize reduction of system size and weight (e.g., avionic, automotive). In view of the dramatic reduction in output filter size that Such frequency increase enable, the developed $\mathrm{SiC}$ power 
module must be regarded as a solution enabling optimum trade-off choices in inverter development.

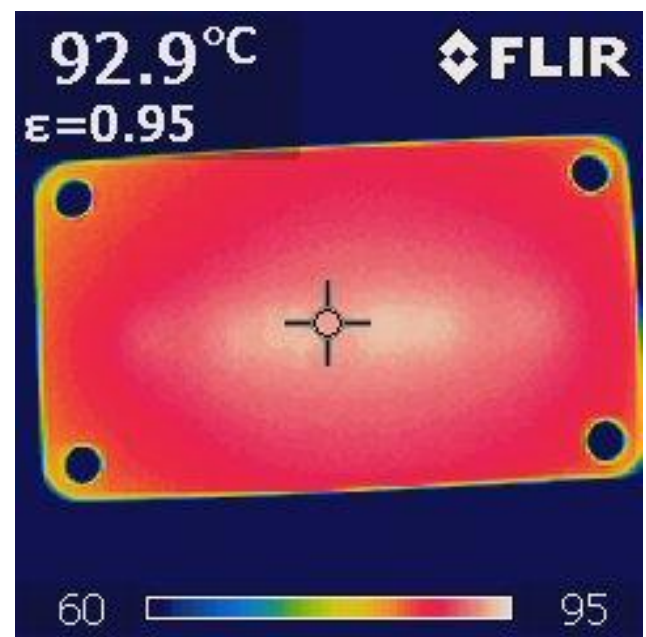

a)

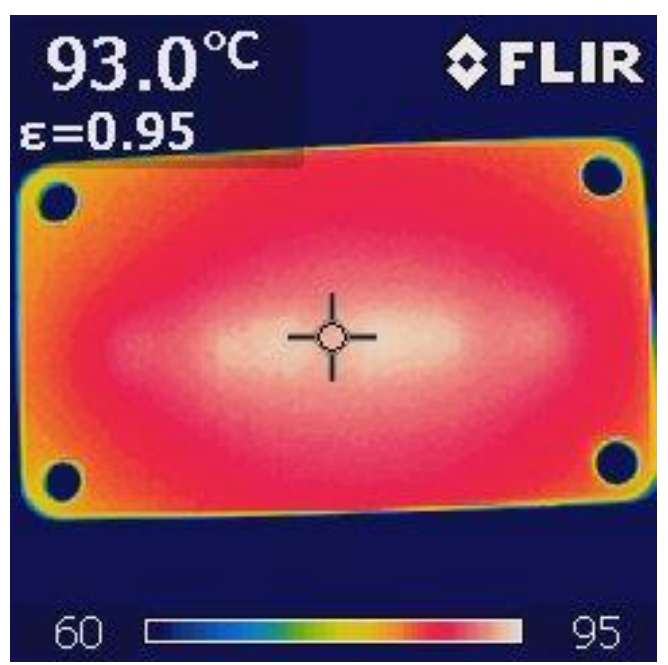

b)

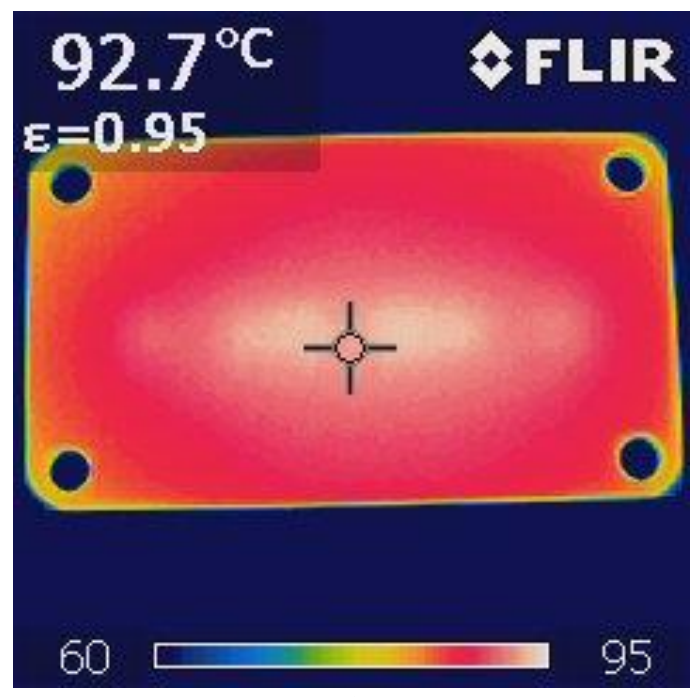

c)

\section{REFERENCES}

[1] A. Zeanh et al., "Thermo mechanical modelling and reliability study of an IGBT module for an aeronautical application." In Proc. $9^{\text {th }}$ Int. Conf. on Thermal, Mechanical and Multiphysics Simulation and Experiments in Micro-Electronics and MicroSystems, EuroSimE 2008.

[2] A. Zeanh et al., "Lifetime and reliability assessment of AlN substrates used in harsh aeronautic environments power switch modules", Advanced Materials Research vol. 112, pp 113-127, 2010 .

[3] W.W. Sheng, R.P. Colino, "Power Electronic Modules: Design and Manufacture", CRC Press LLC, Florida, USA, 2005.

[4] Hui Zhang; Tolbert, L.M.; Jung Hee Han; Chinthavali, M.S.; Barlow, F., "18 kW three phase inverter system using hermetically sealed SiC phase-leg power modules," Applied Power Electronics Conference and Exposition (APEC), 2010 Twenty-Fifth Annual IEEE, pp.1108,1112, 21-25 Feb. 2010.

Fig. 11. Infrared thermal mapping of the module baseplate under different operational conditions: $\mathrm{P}_{\text {OUT }}=2.5 \mathrm{~kW}$ and $\left.\mathrm{f}_{\mathrm{s}}=5 \mathrm{kHz}, \quad \mathrm{a}\right) ; \quad \mathrm{P}_{\text {OUT }}=1.5 \mathrm{~kW}$ at $\left.\mathrm{f}_{\mathrm{s}}=40 \mathrm{kHz}, \quad \mathrm{b}\right)$; $\mathrm{P}_{\text {OUT }}=1.5 \mathrm{~kW}$ at $\left.\mathrm{f}_{\mathrm{s}}=80 \mathrm{kHz}, \mathrm{c}\right)$. 
